\title{
EXPERIMENTAL STUDY OF THE BINARY Ni-RU-SYSTEM USING DIFFUSION COUPLES MANUFACTURED BY ENCAPSULATING CAST
}

\author{
Robert Popp ${ }^{1}$, Rainer Völkl ${ }^{1}$, Thomas Göhler ${ }^{2}$, Uwe Glatzel ${ }^{1}$ \\ ${ }^{1}$ Metals and Alloys, University of Bayreuth, Ludwig-Thoma-Str. 36b, 95447 Bayreuth, Germany \\ ${ }^{2}$ MTU Aero Engines AG, Dachauer Str. 665, 80995 Munich, Germany \\ Keywords: nickel, ruthenium, diffusion couples, solubility limits
}

\begin{abstract}
A novel preparation technique for diffusion couples as well as diffusion multiples has been developed. The approach suitable for phase diagram mapping and the investigation of diffusivities is based on a two-step casting process using a vacuum induction furnace to assemble diffusion samples encapsulated by nickel. The binary $\mathrm{Ni}-\mathrm{Ru}$-system was chosen as a first case study and two equal diffusion couples containing the pure components were prepared. Isothermal annealing at temperatures of $900{ }^{\circ} \mathrm{C}$ and $1100{ }^{\circ} \mathrm{C}$ generated constant interdiffusion zones throughout the contact surfaces of the pure elements. As validation of the new method, the results of the determined solubility limits in both phases are compared to previously published data and are found to be in very good agreement.
\end{abstract}

\section{Introduction}

The performance and efficiency of gas turbine engines is limited by the maximum operating temperature of the turbine blades. Singlecrystal Ni-base superalloys are currently best suited to meet the different requirements in terms of elevated temperatures, high centripetal forces and aggressive atmospheres. For this reason research and development were concentrated in large part on enhancing the working temperature of Ni-base superalloys. Single crystal Ni-base superalloys passed various generations of development; additions of 2-3 wt.\% ruthenium (Ru) led to the major improvement of the $4^{\text {th }}$ generation alloys [1]. Introducing $5^{\text {th }}$ and $6^{\text {th }}$ generation superalloys the content of Ru was even increased to 5-6 wt.\% [2]. Ruthenium is reported to cause rhenium and the refractory elements such as $\mathrm{Mo}, \mathrm{Cr}$ and $\mathrm{W}$ to partition more strongly to the $\gamma^{\prime}$-phase, which is also known as reverse partitioning effect $[1,3]$. Thus the high-temperature microstructure stability is improved and the precipitation of topologically close packed (TCP) phases is reduced $[4,5]$.

Recently the replacement of the experimental approach in alloy development with a more theoretical approach based on simulations is very appealing because of the potential cost and time savings. However, the prediction of microstructure evolution during heat treatment and service is complex due to the multielement alloys generally used. The difficulties arise from the usage of up to 10 elements and the multiphase nature of superalloys, including $\gamma$ matrix, $\gamma^{\prime}$-phase precipitates, carbides and topologically close packed (TCP) phases. Calculating changes in phase distributions and compositions is based on high quality multicomponent thermodynamic and diffusion mobility databases and enables materials properties for a given alloy being predicted during a diffusion simulation.

Elements which segregate strongly, and consequently lead to the formation of TCP-phases, are of particular interest. This is because the depletion of strengthening elements in the matrix and $\gamma^{\prime}$-phase is accompanied with decreasing mechanical properties. Therefore the knowledge of phase equilibria in these systems is of high relevance to the development of new single crystal Ni-based superalloys. The present work concentrates on the refinement of solubility limits and establishes a new fabrication route for diffusion multiples in order to accelerate future investigations in this field.

The diffusion multiple approach proved to be one of the most powerful ways to map phase diagrams [6-8]. Lately many different styles of the diffusion couple method have been reported. Generally two or more materials are brought in such intimate contact and heat treated that they diffuse into each other while local equilibria within the diffusion zone are assumed [6]. Following the heat treatment, the samples are quenched in water and sectioned perpendicular to the bond interface. However, the various approaches of sample manufacturing differ significantly.

One possibility to establish an interdiffusion zone is the reaction of a metallic substrate with a reactive gas atmosphere. Lengauer [9] used this technique to nitrate titanium sheets and subsequently investigated the interactions between nitride phases as surface layers and the core of pure titanium.

A different approach is the cast coating technique described by Savas [10]. Diffusion couples are prepared by pouring a molten alloy under vacuum in a mould with several rods attached to the mould previously. The liquid alloy melts the top ends of the rods and thus interdiffusion zones of both materials are created. Upon solidification the samples are removed from the mould, crosssectioned and analyzed. In contrast to other techniques the diffusivities in molten metals are examined.

Another distinguished method employs a thermo-mechanical simulator as reported in [11] and [12]. Metallic slices with their ends ground and polished are clamped together and heated up to $1200{ }^{\circ} \mathrm{C}$ under an applied compressive load of $2 \mathrm{MPa}$. Performed under vacuum this procedure creates clean welds. As a precaution against oxidation during treatment at elevated temperatures, joined couples are sealed in quartz ampoules under argon, along with several oxygen getters.

The approach established by Tryon [13] and Kulkarni [14] is very similar. However, instead of using a thermo-mechanical simulator the weld is created in a vacuum furnace at $1000{ }^{\circ} \mathrm{C}$ by attaching a load of $20 \mathrm{MPa}$ for $24 \mathrm{~h}$ to a similarly prepared couple of samples. The measures taken against oxidation do not differ significantly from those outlined in the previous paragraph.

In order to assemble diffusion couples as well as diffusion multiples, hot isostatic pressing (HIP) is commonly used $[8,15,16]$. 
Bars of different alloys are prepared by electron discharge machining (EDM) and inserted in cylinders with square openings. The cylinders are closed with two discs using electron beam welding and subjected to the HIP process. Temperatures of $1200{ }^{\circ} \mathrm{C}$ and pressures higher than $140 \mathrm{MPa}$ are applied for $4 \mathrm{~h}$ before the multiples are encapsulated in argon filled quartz tubes to prevent oxidation during long-term annealing.

\section{Experimental Procedure}

\section{Preparation of Diffusion Couples by Encapsulating Cast}

The experimental procedure used in this investigation is a new manufacturing process for diffusion multiples. Ingots of the elements nickel and ruthenium were prepared by melting highpurity Ni $(99,95 \%)$ and $\mathrm{Ru}(99,95 \%)$ using an arc furnace. They were machined into the appropriate cuboidal shapes with dimensions of $5 \cdot 5 \cdot 15 \mathrm{~mm}^{3}$ by electro discharge machining (EDM). With the dimensions of the specimens being several orders of magnitude larger than the desirable diffusion distances it is assumed that pure elements are left after isothermal annealing. To ensure proper contact and to get rid of the re-cast layer on the EDM surfaces, they were ground and finally polished until the roughness average $R_{a}$ was lower than $0,02 \mu \mathrm{m}$. Subsequently the pieces were cleaned with ethanol in an ultrasonic bath for $5 \mathrm{~min}$.

Interstitial contaminants may diffuse to the contact zone and influence the thermodynamic equilibrium during long-term annealing. In order to obtain an assembly that is mechanically stable and isolates any interstitial contaminants, the two specimens were encapsulated by a two-step casting process. For this purpose a vacuum induction furnace working at an air pressure lower than $1 \cdot 10^{-3}$ mbar was used. First the two specimens were brought into contact through the polished surfaces and subsequently they were clamped at the bottom of a cylindrical copper mould with half of their length protruding. For the first casting campaign nickel melts were poured under vacuum into the mould at $25^{\circ} \mathrm{C}$. During subsequent cooling the shrinkage leads to a firm contact between the specimens. Nickel was used as a capsule due to its excellent castability and a melting point well beyond the aspired isothermal annealing temperatures. A diffusion couple after the first step, half covered in a cast nickel cylinder, is shown in Fig. 1.

To complete the nickel-shell from the opposite side the half-encapsulated diffusion couples were placed into ceramic shell moulds of the same size. Before nickel melts were poured under vacuum into the moulds they were preheated to $1450{ }^{\circ} \mathrm{C}$, thus the quality of the joints is excellent. The time for the specimens at elevated temperatures during preheating and casting comes to a maximum of 15 minutes, which is considerably less in comparison to other techniques. Therefore the extent of the interdiffusion zone at this point is assumed to be negligible in contrast to the final state after annealing. After the second step, the resultant cylinder, $20 \mathrm{~mm}$ in diameter, was cut to a length of $25 \mathrm{~mm}$. The completely assembled setup is shown in Fig. 2 with the encapsulated diffusion couple drawn schematically. The joined surfaces of the two casting steps are barely visible by an edge on the surface and marked by an arrow

\section{Isothermal Annealing}

Subsequently the fully assembled couples, as shown in Fig. 2, were annealed at the temperature of interest in order to enable diffusion

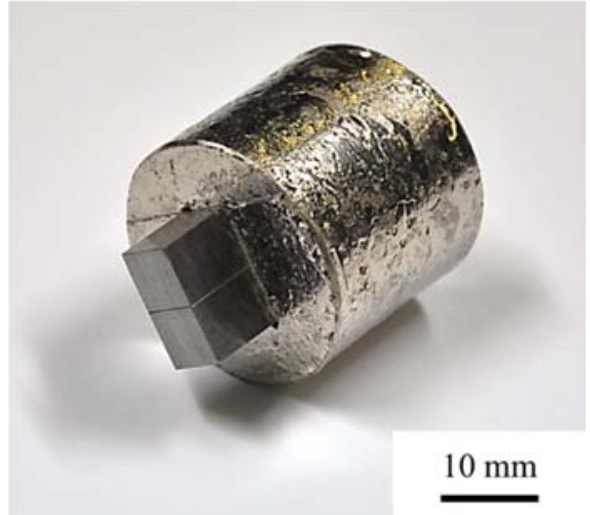

Figure 1: Two diffusion specimens clamped together after the first casting campaign and half-encapsulated in a cast nickel cylinder.

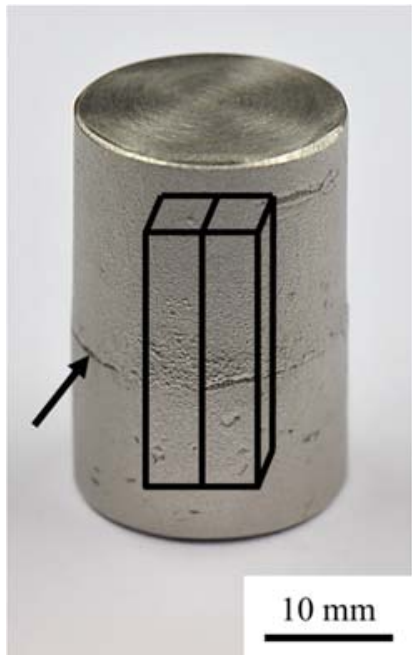

Figure 2: Completely encapsulated diffusion couple (hidden couple indicated schematically) after the second casting campaign. Arrow indicates the location where first and second casting surfaces meet

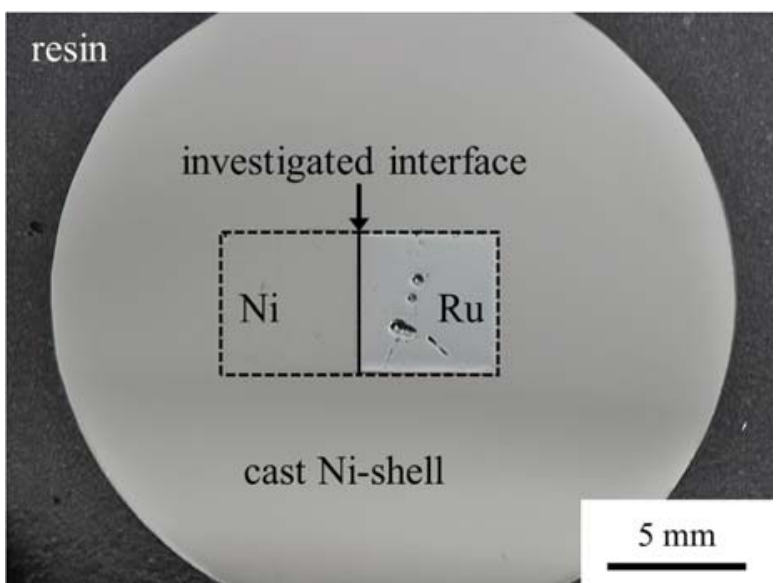

Figure 3: Photograph of the cross-sectioned diffusion couple after being annealed at $900{ }^{\circ} \mathrm{C}$ for $300 \mathrm{~h}$. The two specimens ( $\mathrm{Ni}$ on the left, $\mathrm{Ru}$ on the right) embedded in the cast nickel-shell are marked with broken lines for better visibility. 
of each material into the other. In contrast to other approaches [11-16] the diffusion couples encapsulated by casting do not require further precautions against oxidation of the specimens' interface. The applied temperature profiles consist of two parts, see Zhao et al. [8]. First the samples were heated up to $1200{ }^{\circ} \mathrm{C}$ and kept at this temperature for $4 \mathrm{~h}$ to initialize an interdiffusion zone. Thereafter, the temperature was decreased to the isothermal annealing temperature in the second part, namely $900{ }^{\circ} \mathrm{C}$ and $1100{ }^{\circ} \mathrm{C}$, and held for $300 \mathrm{~h}$. During this period the interdiffusion zone expands and thermodynamic equilibrium at the interface is achieved. After the heat treatment, water quenching of the samples was necessary in order to freeze in the high-temperature state and to prevent further diffusion.

\section{Analytical Techniques}

After annealing and quenching, the diffusion couples were crosssectioned, embedded in a conductive resin and polished to a final finish with $1 \mu \mathrm{m}$ diamond slurry, as shown in Fig. 3. The interface of the phases could be seen using backscatter electron (BSE) imaging due to the differences in their average atomic weight. The chemical analyses were performed on a Thermo Noran energydispersive X-ray (EDX) spectrometer attached to a scanning electron microscope (SEM) using an accelerating voltage of $15 \mathrm{kV}$.

\section{Results and Analysis}

During isothermal annealing the Ni-cylinders are oxidized and oxide-layers of $\mathrm{NiO}$ and $\mathrm{Ni}_{2} \mathrm{O}_{3}$ are formed on the surfaces at $900{ }^{\circ} \mathrm{C}$ and $1100{ }^{\circ} \mathrm{C}$, respectively. Both kinds of oxides cover up the entire cylinder and are stable. Examination of the cross-sections show very thin oxide-layers compared to the thickness of the nickel capsule and therefore indicate, that the given setup allows considerably longer annealing times without any problem.

The contact surfaces of the nickel and the ruthenium specimen were examined using BSE imaging in the SEM. A continuous interface of the two phases is observable on the whole length of the couples and no oxides could be detected. This proves the excellent contact and reasonable air pressure during manufacture. Subsequently, EDX measurements were carried out, confirming a constant zone of interdiffusion. Fig. 4 shows the Ni-Ru-interface of the diffusion couple annealed at $1100{ }^{\circ} \mathrm{C}$ for $300 \mathrm{~h}$. The arrow in the box shaded in grey represents the direction of EDX-linescans (Fig. 5 and 6) performed vertical to the interface to investigate the concentration profiles in the interdiffusion zones.

Fig. 5 and Fig. 6 represent the results of EDX-linescans measured for the samples annealed at $900{ }^{\circ} \mathrm{C}$ and $1100{ }^{\circ} \mathrm{C}$, respectively. As indicated by the rectangle surrounding the arrow in Fig. 4 , the linescans are averaged over a certain width to smooth out the concentration profiles. The interface of both phases is indicated by the sharp drop in the concentration profiles, which expands to a width of 2-3 $\mu \mathrm{m}$ due to the unevenness of the interface. As expected the interdiffusion zone grew wider at a temperature of $1100{ }^{\circ} \mathrm{C}$ compared to the result at $900{ }^{\circ} \mathrm{C}$, namely $150 \mu \mathrm{m}$ in contrast to $25 \mu \mathrm{m}$. However, both experiments provide sufficient areas to apply the previously described analytical techniques.

According to theory, thermodynamic equilibrium is achieved at the interface of two phases during annealing. Water quenching conserves the high-temperature concentration profile and enables

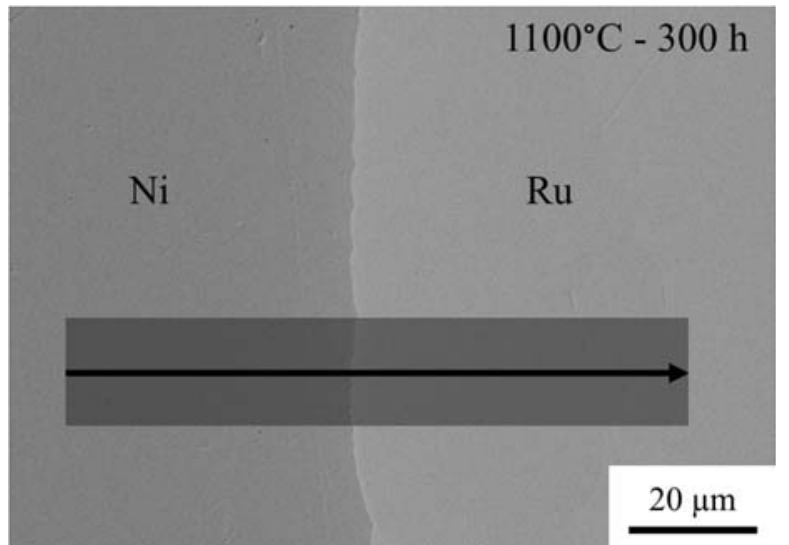

Figure 4: Microstructure of the diffusion zone after annealing at $1100{ }^{\circ} \mathrm{C}$ for $300 \mathrm{~h}$. Secondary electron image of the interface between nickel on the left and ruthenium on the right. The arrow represents the direction of the EDX-linescans shown in Fig. 5 and Fig. 6.

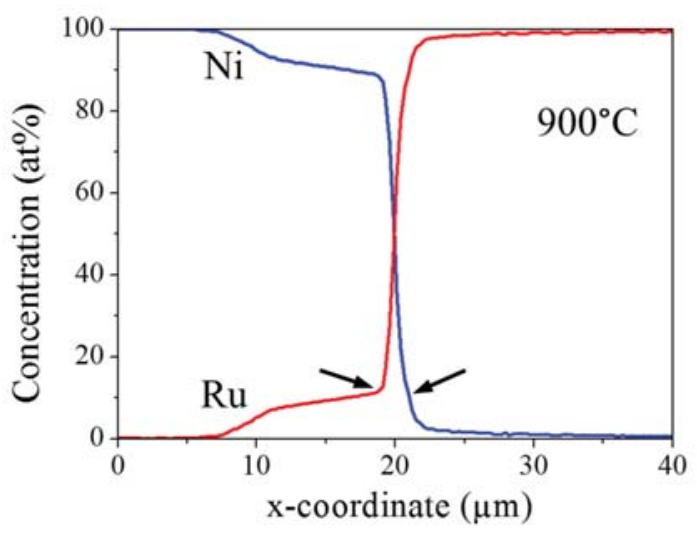

Figure 5: Concentration profile vertical to the Ni-Ru-interface of the diffusion couple annealed at $900{ }^{\circ} \mathrm{C}$ for $300 \mathrm{~h}$ measured by EDX. Solubility limits indicated by arrows.

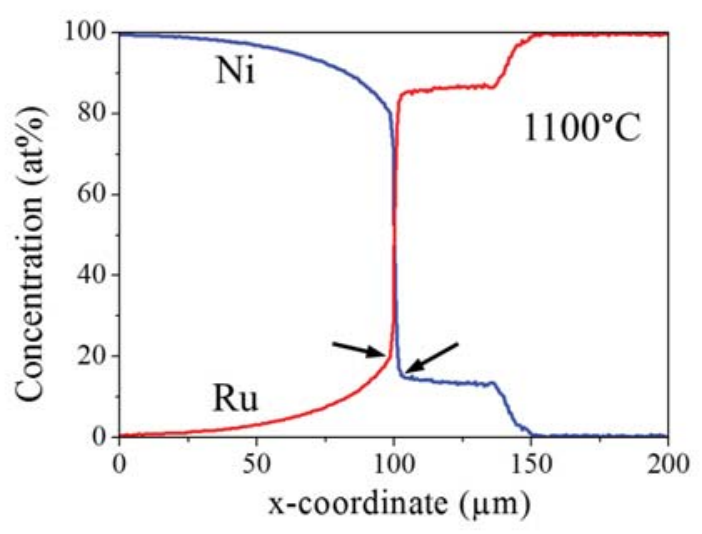

Figure 6: Concentration profile vertical to the Ni-Ru-interface of the diffusion couple annealed at $1100{ }^{\circ} \mathrm{C}$ for $300 \mathrm{~h}$ measured by EDX. Solubility limits indicated by arrows. 


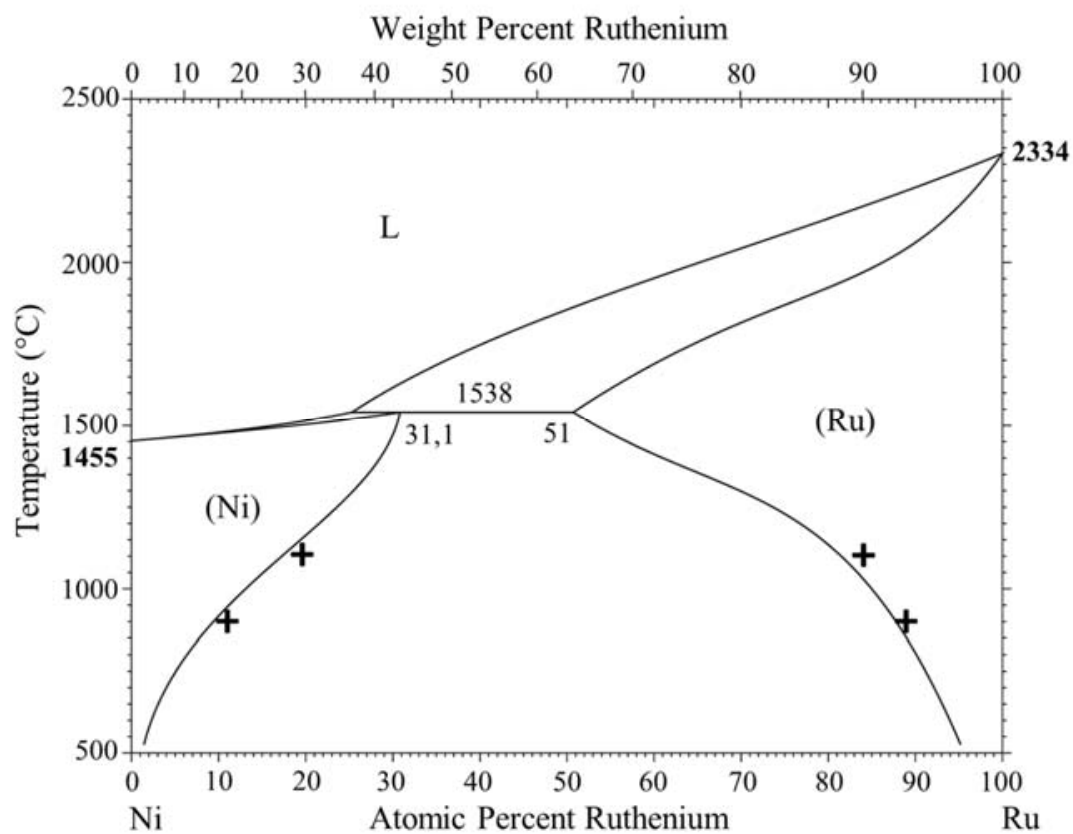

Figure 7: Ni-Ru phase diagram assessed by Hallström et al. [21], taken from [22]. The determined solubility limits for both phases at $900{ }^{\circ} \mathrm{C}$ and $1100{ }^{\circ} \mathrm{C}$ from the present work are added as "+" signs in the diagram.

its examination. Therefore the determination of the phase boundary data by analyzing the concentrations at the interface is practicable. In Fig. 5 and Fig. 6 these data points are marked by arrows. The measurements indicate a solubility limit of 11.0 at. $\%$ at $900{ }^{\circ} \mathrm{C}$ and 19.5 at. $\%$ at $1100{ }^{\circ} \mathrm{C}$ of $\mathrm{Ru}$ in $\mathrm{Ni}$ (disordered fcc-A1 phase). The maximum solubility of $\mathrm{Ni}$ in $\mathrm{Ru}$ (hcp-A3 phase) appears to be 15.5 at. $\%$ at a temperature of $1100{ }^{\circ} \mathrm{C}$. All data were verified by point measurements as close to the interface as possible considering the activation volume. At a temperature of $900{ }^{\circ} \mathrm{C}$ the results indicate a solubility limit of 10.8 at.\% of $\mathrm{Ni}$ in Ru. However, a degree of uncertainty remains in this measurement since the concentration profiles in the ruthenium phase corresponding to Fig. 5 are very steep which makes it considerably more difficult to quantify accurate data. Adequate information could be obtained from an identically assembled sample which is annealed for a longer period of time and therefore provides a flattened concentration profile. Furthermore, the concentration profiles in Fig. 6 show a second drop after a $35 \mu$ m wide segment to the right of the phase boundary. The concentrations in this section show a very small slope. The reasons leading to this observation are currently subject of further investigations.

\section{Discussion}

The Ni-Ru binary phase diagram is a simple peritectic type with extensive solubility of $\mathrm{Ru}$ in $\mathrm{Ni}$ and vice versa. The liquidus and solidus as well as the solvus have been previously investigated by thermal analysis, X-ray diffraction and microscopy and published $[17,18]$. The system has also repeatedly been thermodynamically modeled over the last decades $[19,20]$ and Hallström et al. [21] finally published a description that reproduces well the preceding experimental data. Fig. 7 shows the Ni-Ru phase diagram assessed by Hallström et al. [21]. In addition the diagram is complemented with the phase boundary data for both phases at $900{ }^{\circ} \mathrm{C}$ and $1100{ }^{\circ} \mathrm{C}$ determined by the present work.
As Fig. 7 shows, the solubility limits suggested in the previous section differ slightly from the phase diagram assessed by Hallström et al. [21]. The specified values indicate both phase borders to be shifted to higher ruthenium concentrations. However, the deviation in all points is less than 3 at.\%. Since there are only two experimental data published $[17,18]$ that also show significant variance, as pointed out by Danilenko [20], a degree of uncertainty still remains in Hallströms calculations. In the light of this the slight difference that becomes apparent in Fig. 7 is on a very small scale. Therefore it is certainly true to say that the determinations of the present work are in good accordance with the previously published data and the introduced preparation technique for diffusion couples is reliable.

\section{Outlook}

The authors are convinced that diffusion multiples manufactured by encapsulating cast hold great potential to accelerate phase diagram mapping in the future. Since the solubility limits can be

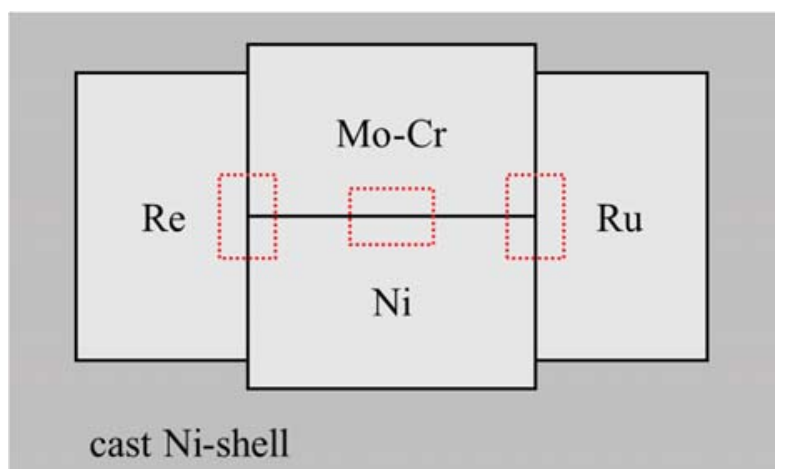

Figure 8: Schematic drawing of a diffusion multiple with four specimens in a cast nickel shell. Microstructures of the marked areas after annealing are shown in Figs. 10 and 11. 


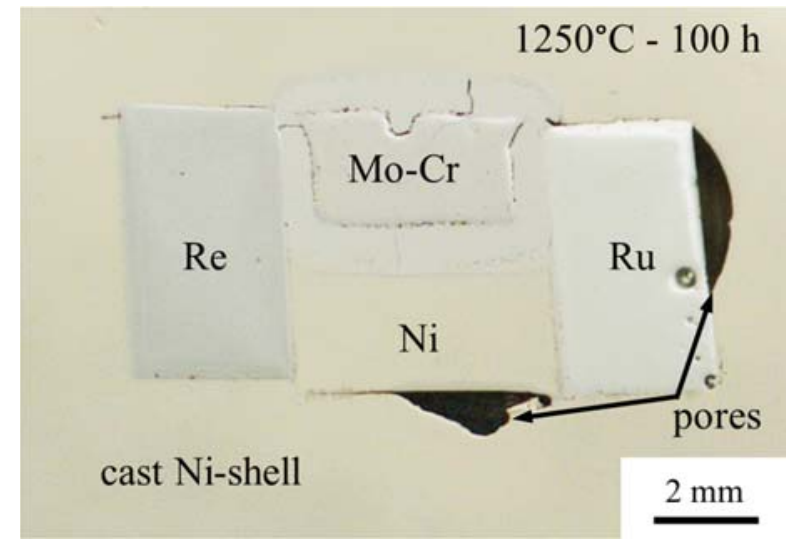

Figure 9: Photograph of the cross-section of a diffusion multiple with four specimens after being annealed at $1250{ }^{\circ} \mathrm{C}$ for $100 \mathrm{~h}$. The diffusion-multiple was manufactured by cast-encapsulation.

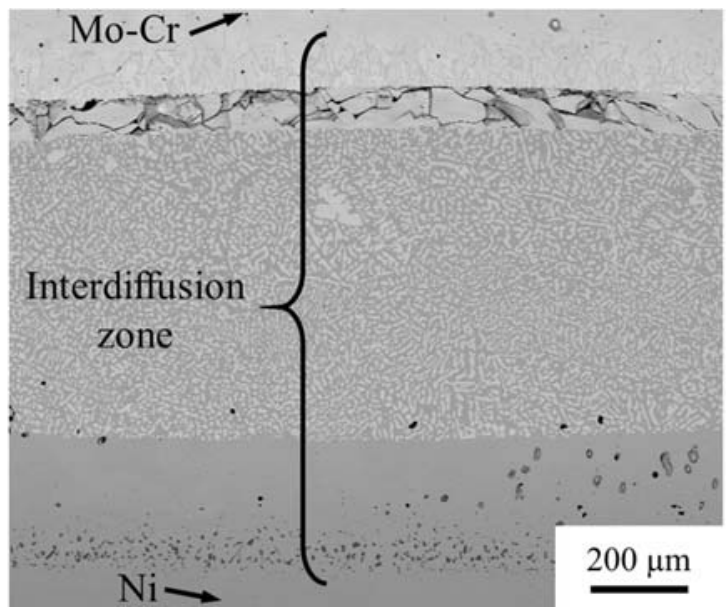

Figure 10: Microstructure of the interdiffusion zone of the middle section marked in Fig. 8. Back-scatter electron image of the interface between the molybdenum-chromium solid solution on the top and nickel at the bottom.

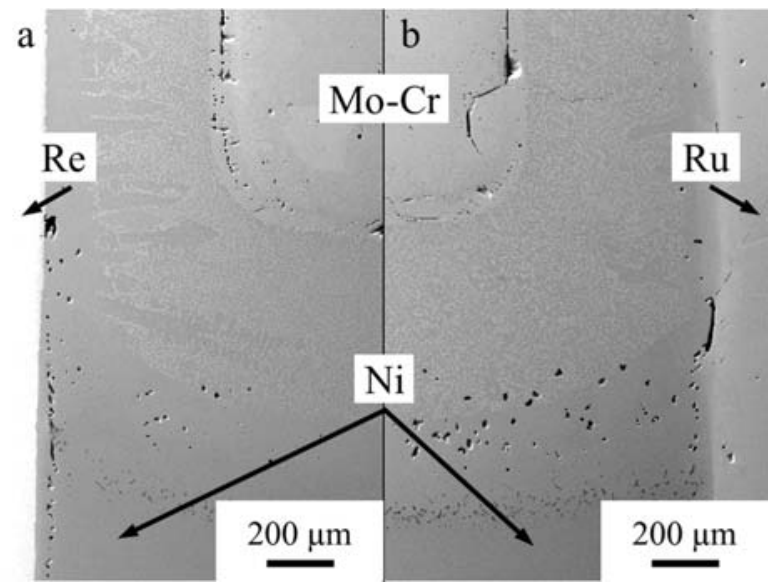

Figure 11: Microstructure of interdiffusion zones with three specimens as marked in Fig. 8. The molybdenum-chromium solid solution and nickel form a horizontal interface with (a) rhenium on the left and (b) ruthenium on the right. taken from the concentrations at the phase boundaries, the reliability of the determined data depends on the quality of the measurement method. Therefore, future investigations will be carried out using transmission electron microscopy (TEM), as the analytical volume is considerably reduced in comparison to scanning electron microscopy (SEM). However, TEM investigations are bound to extensive preparation processes. TEM lamella preparation by focused ion beam (FIB) is best suited for this application as lamellas can be taken very precisely at a certain point of interest. Considering Fig. 4, a lamella preparation vertical to the phase boundary would be desirable.

Furthermore the described manufacturing technique by cast-encapsulation has already been successfully applied for assembling diffusion multiples. The setup is easily adapted to different numbers of samples or different sized samples. The device to clamp the specimens at the bottom of the cylindrical copper mould is the only part that requires adjustments. Fig. 8 shows a schematic drawing of the cross section of a diffusion multiple manufactured by encapsulating cast. Rhenium, ruthenium, nickel, molybdenum and chromium are the elements used in this assembly. The drawing gives an example of how four specimens can be assembled, including both single-phase and solid solution. The entire setup includes five interfaces of two specimens and two points where three specimens meet. Therefore, an assembly as shown in Fig. 8 holds an enormous information content. Fig. 9 shows a photograph of the cross-sectioned diffusion multiple. As the photograph is taken after annealing the interdiffusion zones between the specimens are already visible. The pores in the cast $\mathrm{Ni}$-shell on the outside of the $\mathrm{Ni}$ - and the $\mathrm{Ru}$-specimen are not critical. The microstructure, which formed at the marked sections of Fig. 8, is shown in detail in Figs. 10 and 11. As it can be seen the interdiffusion zones grew to an extent of more than $1 \mathrm{~mm}$ and consist of both, single-phase and two-phase regions. Continuous interdiffusion zones can be observed at all interfaces of two specimens (e.g. Fig. 10) as well as at both tri-junction areas (Fig. 11). Phase characterization and analyses of phase compositions is currently in progress.

\section{Summary and Conclusions}

A new manufacturing process for solid-solid diffusion couples has been developed. The method involves a two-step casting process to encapsulate the samples. Thus, the samples are brought into firm contact and prevented from oxidation for long-term annealing. The presented procedure was used for an experimental study of the binary Ni-Ru-system. A comparison of the findings to previously published data is drawn and shows encouraging results. As the process has already been successfully applied to assemble diffusion multiples it is very well suited for future phase diagram imaging.

\section{Acknowledgement}

The authors thank the Federal Ministry for Economic Affairs and Energy (BMWi) and the company MTU Aero Engines AG for funding this work as part of the research initiative "LuFo V - MatSim".

\section{References}

1. S. Walston et al., "Joint Development of a Fourth Generation Single Crystal Superalloy", Superalloys 2004, (TMS, 2004), pp. $15-24$. 
2. K. Kawagishi et al., "Development of an Oxidation-Resistant high-strength sixth-Generation Single-Crystal Superalloy TMS238", Superalloys 2012, (TMS, 2012), pp. 189-195.

3. S. Neumeier, F. Pyczak and M. Göken, "The Influence of Ruthenium and Rhenium on the Local Properties of the $\gamma$ - and $\gamma^{\prime}$ phase in Nickel-Base Superalloys and their Consequences for Alloy Behavior", Superalloys 2008, (TMS, 2008), pp. 109-119.

4. A. Sato et al., "TTT Diagram for TCP Phases Precipitations of $4^{\text {th }}$ Generation Ni-Base Superalloys", Journal of the Japan Institute of Metals, 68 (2004), pp. 507-510.

5. Z. Shi, J. Li and S. Liu, "Effects of Ru on the Microstructure and Phase Stability of a Single Crystal Superalloy", International Journal of Minerals, Metallurgy and Materials, 19 (11) (2012), pp. 1004-1009.

6. A.A. Kodentsov, G.F. Bastin and F.J.J. van Loo, "The diffusion couple technique in phase diagram determination", Journal of Alloys and Compounds, 320 (2001), pp. 207-217.

7. J.-C. Zhao, "The diffusion-multiple approach to designing alloys", Annual Review of Materials Research, 35 (2005), pp. 5173.

8. J.-C. Zhao, M.R. Jackson and L.A. Peluso, "Determination of the $\mathrm{Nb}-\mathrm{Cr}-\mathrm{Si}$ phase diagram using diffusion multiples", Acta Materialia, 51 (20) (2003), pp. 51-73.

9. W. Lengauer, "The titanium-nitrogen system: A study of phase reactions in the subnitride region by means of diffusion couples", Acta Metallurgica et Materialia, 39 (1991), pp. 2985-2996.

10. M.A. Savas et al., "Diffusion couple preparation using cast coating technique", Journal of Materials Science, 37 (2002), pp. 4093-4099.

11. M.S.A. Karunaratne and R.C. Reed, "Interdiffusion of the platinum-group metals in nickel at elevated temperatures", Acta Materialia, 51 (10) (2003), pp. 2905-2919.

12. R.A. Hobbs et al., "Uphill diffusion in ternary Ni-Re-Ru alloys at 1000 and $1100{ }^{\circ} \mathrm{C} "$, Materials Science and Engineering A, 460461 (2007), pp. 587-594.

13. B. Tryon and T.M. Pollock, "Experimental assessment of the Ru-Al-Ni ternary phase diagram at 1000 and $1100{ }^{\circ} \mathrm{C}$ ", Materials Science and Engineering A, 430 (2006), pp. 266-276.

14. K.N. Kulkarni et al., "Ternary Diffusion in a RuAl-NiAl Couple", Journal of Phase Equilibria and Diffusion, 28 (6) (2007), pp. 503-509.

15. J.-C. Zhao, M.R. Jackson and L.A. Peluso, "Mapping of the NbTi-Si phase diagram using diffusion multiples", Materials Science and Engineering A, 372 (2004), pp.21-27.

16. C.E. Campbell, J.-C. Zhao and M.F. Henry, "Examination of Ni-base superalloy diffusion couples containing multiphase regions", Materials Science and Engineering A, 407 (2005), pp. $135-146$.
17. I.I Kornilov and K.P. Myasnikova, "Phase diagram and physical properties of nickel-ruthenium alloys", Russian Metallurgy and Mining, 4 (1964), pp. 95-101.

18. E. Raub and D. Menzel, "Die Nickel-Ruthenium Legierungen", Zeitschrift für Metallkunde, 52 (1961), pp. 831-833.

19. A.A. Ovcharenko, "Computer Calculation of the Constitution Diagrams of Cerain Binary Alloys with Determination of Interaction Parameters from Experimental Diagrams", The Physics of Meals and Metallography, 49 (5) (1980), pp. 1013-1020.

20. V.M. Danilenko et al., "Thermodynamic simulation of the NiRu binary-system phase diagram", Powder Metallurgy and Metal Ceramics, 38 (5-6) (1999), pp. 254-260.

21. S. Hallström et al., "Thermodynamic Reassessment of the Ni$\mathrm{Ru}$ System and Assessment of the Al-Ni-Ru System at 1273$1523 \mathrm{~K}$ using ab initio calculations”, Acta Materialia, 56 (15) (2008), pp. 4062-4069.

22. H. Okamoto, "Ni-Ru (Nickel-Ruthenium)", Journal of Phase Equilibria and Diffusion, 30 (4) (2009), pp. 412-412. 